\title{
Captopril and atenolol are equally effective in retarding progression of diabetic nephropathy
}

\section{Results of a 2-year prospective, randomized study}

\author{
L.D. Elving ${ }^{1}$, J. F. M. Wetzels ${ }^{2}$, H.J.J.van Lier ${ }^{3}$, E.de Nobel ${ }^{1}$, J.H.M. Berden ${ }^{2}$ \\ ${ }^{1}$ Department of Medicine, Division of General Internal Medicine, University Hospital Nijmegen, Nijmegen, The Netherlands \\ ${ }^{2}$ Department of Medicine, Division of Nephrology, University Hospital Nijmegen, Nijmegen, The Netherlands \\ ${ }^{3}$ Department of Medical Statistics, University of Nijmegen, Nijmegen, The Netherlands
}

\begin{abstract}
Summary The progression of diabetic nephropathy can be positively influenced by maintaining a low blood pressure level. This has been shown in studies with conventional antihypertensive treatment as well as with ACE inhibitors. Whether the latter group of drugs is more effective remains to be proven and was the aim of our study. In a prospective randomized study we compared the effects of ACE inhibition and $\beta$-blockade on retarding progression of renal function in IDDM patients with an early stage of overt diabetic nephropathy. Twenty-nine patients were studied for 2 years, 15 were randomized for treatment with captopril and 14 for atenolol. Every 6 weeks blood pressure and urinary albumin and total protein excretion were measured. GFR was measured every 6 months as ${ }^{51} \mathrm{Cr}$-EDTA clearance. Baseline values for blood pressure, renal function and albuminuria were identical in the two groups. The effect of both drugs on blood pressure was not significantly different. In the captopril-treated patients MAP before
\end{abstract}

and after 2 years was $110 \pm 3(\mathrm{SEM})$ and $100 \pm 2 \mathrm{~mm} \mathrm{Hg}$, respectively and in the atenolol-treated patients $105 \pm 2$ vs $101 \pm 2 \mathrm{~mm} \mathrm{Hg}$. Both drugs reduced albuminuria and total proteinuria to the same extent. With captopril albuminuria decreased from $1549(989-2399)$ to 851 $(537-1380) \mathrm{mg} / 24 \mathrm{~h}$ and proteinuria from $2.5(1.6-3.8)$ to $1.2(0.8-1.8) \mathrm{g} / 24 \mathrm{~h}$. With atenolol albuminuria decreased from $933(603-1445)$ to $676(437-1047) \mathrm{mg} /$ $24 \mathrm{~h}$ and proteinuria from $1.5(1.0-2.4)$ to $0.9(0.6-$ $1.5) \mathrm{g} / 24 \mathrm{~h}$. The rate of decline of GFR was similar with both treatments, on captopril $-4.9 \pm 2.1$ and on atenolol $-3.7 \pm 1.6 \mathrm{ml} \cdot \mathrm{min}^{-1} \cdot$ year $^{-1}$. No major side effects with either drug were observed. We conclude that, in this 2-year study, captopril and atenolol are equally effective in retarding progression of diabetic nephropathy. [Diabetologia (1994) 37: 604-609]

Key words IDDM, diabetic nephropathy, glomerular filtration rate, albuminuria, captopril, atenolol.
During the 1980's it became clear that antihypertensive treatment attenuates deterioration of renal function in patients with diabetic nephropathy $[1,2]$. It has been suggested that intraglomerular hypertension caused by

Received: 28 September 1993

and in revised form: 29 December 1993

Corresponding author: Dr. L.D.Elving, Department of Medicine, Division of General Internal Medicine, University Hospital Nijmegen, P.O. Box 9101, 6500 HB Nijmegen, The Netherlands

Abbreviations: IDDM, insulin-dependent diabetes mellitus; $\mathrm{ACE}$, angiotensin converting enzyme; ECC, endogenous creatinine clearance; MAP, mean arterial pressure; GFR, glomerular filtration rate vasodilation of the afferent arteriole contributes to the pathogenesis of diabetic glomerular sclerosis [3]. Hence, antihypertensive drugs that can reduce intraglomerular pressure, may be of special benefit in the treatment of patients with diabetic nephropathy. Therefore, ACE inhibitors, which decrease the intraglomerular capillary pressure by blocking the effect of angiotensin II on the efferent arteriole, might be superior to other antihypertensive drugs. Indeed, in patients with severe diabetic nephropathy addition of captopril to the antihypertensive regimen, reduced proteinuria without further effect on blood pressure [4]. In proteinuric diabetic patients with normal blood pressure and normal renal function, we found that captopril acutely lowered albuminuria without lowering blood pressure [5]. These studies suggest a specific in- 
traglomerular effect of ACE inhibitors in patients with diabetic nephropathy. Whether long-term treatment of overt diabetic nephropathy with ACE inhibitors is superior to other antihypertensive drugs remains to be proven. We have performed a prospective, randomized, controlled study comparing the effects of ACE inhibition with $\beta$-blocker therapy on the decline of GFR and on albuminuria in patients with an early stage of overt diabetic nephropathy.

\section{Patients and methods}

\section{Patients}

From a population of 530 IDDM patients who regularly visited the out-patient diabetic clinic of the University Hospital Nijmegen between April 1988 and April 1990, 73 patients with signs of overt diabetic nephropathy were selected. IDDM was defined as age at onset of diabetes before 30 years and start of insulin treatment within 1 year of diagnosis. Overt diabetic nephropathy was defined as albuminuria greater than $300 \mathrm{mg} / 24 \mathrm{~h}$ in at least three urine samples, in the absence of urinary tract infection. Other types of renal disease were excluded on the basis of medical history, duration of diabetes of more than 10 years and the presence of diabetic retinopathy. Exclusion criteria for entry to the study were: age below 18 or above 60 years, pregnancy or wish to become pregnant in the near future, ECC less than $30 \mathrm{ml} / \mathrm{min}$, use of two or more antihypertensive drugs, coronary heart disease or congestive heart failure, chronic obstructive pulmonary disease, regular use of non-steroidal anti-inflammatory drugs or proven non-compliance. The study protocol was approved by the local ethical committee and all patients gave written informed consent.

\section{Study design}

All previous antihypertensive medication was stopped for at least 6 weeks before entry into the study. Thereafter, baseline laboratory parameters were determined. Patients were allocated for treatment with either captopril or atenolol with the standardized variance method [6], balancing for the following factors: age, sex, duration of diabetes, blood pressure, proteinuria, $\mathrm{ECC}, \mathrm{HbA}_{1 \mathrm{c}}$ and smoking. Captopril was started at a dose of $25 \mathrm{mg}$ twice daily and increased to $50 \mathrm{mg}$ twice daily. Atenolol was started at a dose of $50 \mathrm{mg}$ once daily and increased to $100 \mathrm{mg}$ once daily. All patients received the maximal dosage except when ECC was less than $50 \mathrm{ml} / \mathrm{min}$ or when supine systolic blood pressure dropped below $110 \mathrm{~mm} \mathrm{Hg}$. When on two consecutive visits MAP was above $110 \mathrm{~mm} \mathrm{Hg}$, chlortalidone $25 \mathrm{mg}$ once daily, was added to the medication. If necessary, this dose was increased to $50 \mathrm{mg}$ once daily. All the patients were studied for 2 years. During this period they continued their usual diet without salt restriction. Patients visited the out-patient clinic every 6 weeks. MAP was measured with an automatic recorder (Dinamap, Criticon Inc., Tampa, Fla., USA), ten recordings during $20 \mathrm{~min}$ in the supine position. Thereafter blood pressure was measured with a sphygmomanometer two times in the supine position and two times after 1 min standing. Every 6 weeks a 24-h urine sample was analysed for creatinine, albumin, total protein and sodium and a blood sample was tested for sodium, potassium, creatinine and $\mathrm{HbA}_{1 \mathrm{c}}$. Every 3 months plasma renin activity, total and HDL-cholesterol, albumin and haemoglobin levels were measured. Before the start of the treatment and at 6-month intervals GFR was measured.

\section{Measurements}

Urinary albumin concentration was measured by laser immunonephelometry as previously described [7] (interassay variation $3 \%$ ). $\mathrm{HbA}_{1 \mathrm{c}}$ was measured by HPLC (normal less than $6.2 \%$ ). Plasma renin activity was measured by radioimmunoassay [8]. Other laboratory parameters were measured using standard techniques. GFR was calculated from the plasma disappearance curve after a single i.v. injection of $100 \mu \mathrm{Ci}^{51} \mathrm{Cr}$ EDTA [9]. Plasma samples were obtained after 180, 200, 220 and 240 min. The coefficient of variation of repeated measurements in patients with stable renal function is $5 \%$. All GFR measurements were performed in the morning under normoglycaemic conditions (glucose level 3.5-8 mmol/l). Patients took their usual morning insulin before breakfast and received i.v. insulin and glucose if necessary to obtain and maintain a normal, stable blood glucose level. The glucose level was measured every 30 min during the procedure (Reflolux 3M; Boehringer Mannheim, Mannheim, Germany).

\section{Statistical analysis}

For comparison of the two treatments a distribution-free test for curve analysis was applied [10]. Within each treatment group comparisons were made using Wilcoxon's signed rank test. The rate of change in GFR $\left(\mathrm{ml} \cdot \mathrm{min}^{-1} \cdot\right.$ year $\left.^{-1}\right)$ was calculated by linear regression analysis on all GFR values in each subject. Correlations were calculated as Spearman correlation coefficients. Values are given as means with SEM. Albuminuria and total proteinuria are given as geometric means (antilog 95\% confidence interval of the logarithms). $P$ values of 0.05 or less were considered significant.

\section{Results}

Of the 73 patients with diabetic nephropathy, 30 patients fulfilled the entrance criteria and all agreed to participate in the study. Twenty-nine patients completed the 2-year study protocol. One patient (female, aged 49 years, no.22) who was randomized for treatment with atenolol experienced severe headache during the first 2 weeks of treatment. After cessation of atenolol the headache immediately resolved and returned upon re-challenge. Thus, she was excluded from further study. The two treatment groups were well matched for the balancing factors. Fifteen patients (12 males/3 females) received captopril, the mean age was $37 \pm 2$ years and duration of diabetes was $26 \pm 2$ years. Fourteen patients ( 11 males/ 3 females) received atenolol, the age of these patients was $39 \pm 3$ years and duration of diabetes was $26 \pm 2$ years. All the patients had signs of retinopathy. Eleven patients had hypertension (defined as blood pressure above $140 / 90 \mathrm{~mm} \mathrm{Hg}$ ) before start of the study. Five had been treated with antihypertensive drugs previously, either captopril (4) or enalapril (1). Of these 
Table 1. Effects of 2-year antihypertensive treatment with captopril or atenolol on haemodynamic and metabolic parameters and renal function

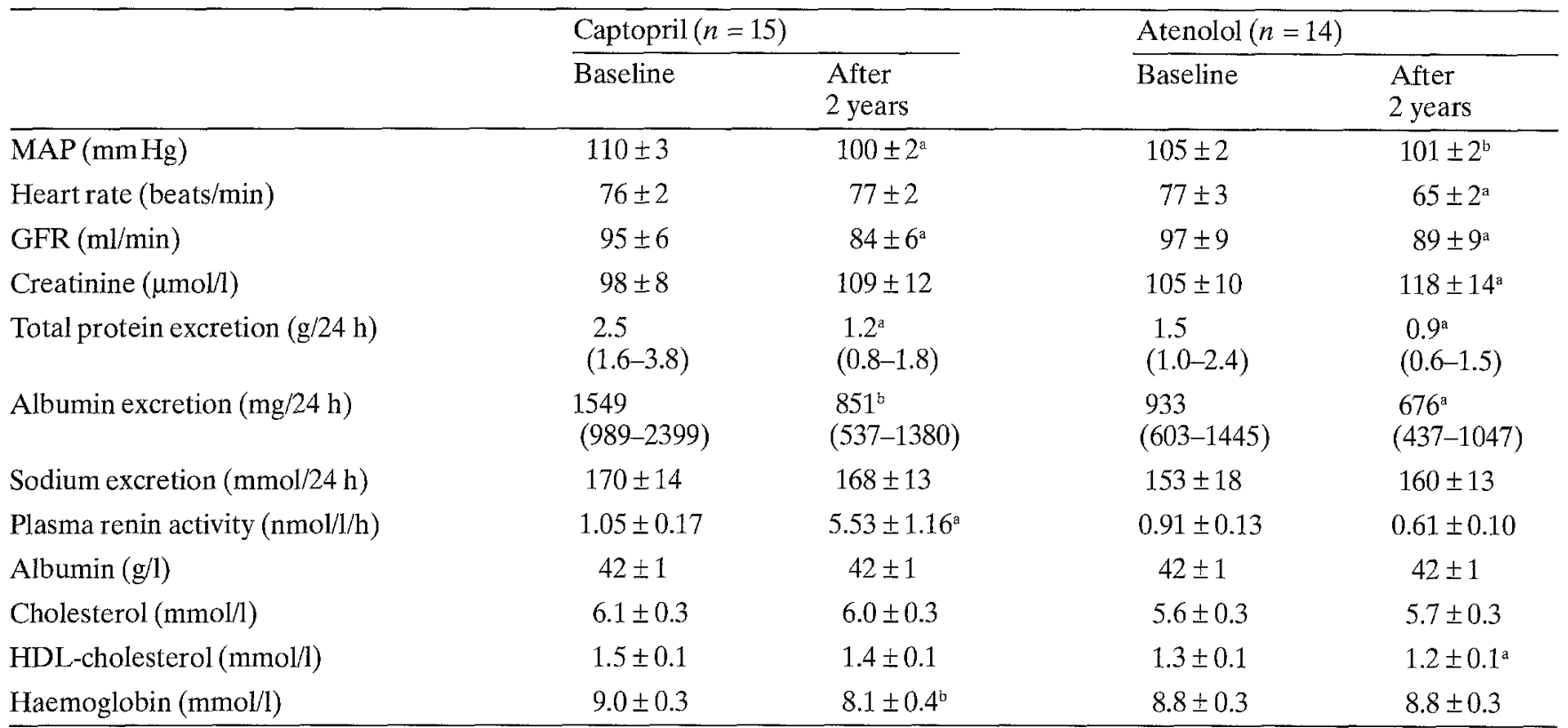

Results after 2 years are the mean of all values measured during the last 6 months of the study

Results are given as mean \pm SEM except for albumin excretion

Table 2. Changes in albuminuria ( $\triangle \mathrm{Alb} ; \%)$ and rates of change in GFR $\left(\triangle \mathrm{GFR} ; \mathrm{ml} \cdot \mathrm{min}^{-1} \cdot \mathrm{year}^{-1}\right)$ in patients with diabetic nephropathy who were treated for 2 years with captopril or atenolol

\begin{tabular}{|c|c|c|c|c|c|}
\hline \multicolumn{3}{|c|}{ Captopril } & \multicolumn{3}{|c|}{ Atenolol } \\
\hline $\begin{array}{l}\text { Patient } \\
\text { no. }\end{array}$ & $\Delta \mathrm{Alb}$ & $\Delta \mathrm{GFR}$ & $\begin{array}{l}\text { Patient } \\
\text { no. }\end{array}$ & $\Delta \mathrm{Alb}$ & $\Delta \mathrm{GFR}$ \\
\hline 1 & +291 & -5.8 & 2 & -34 & -10.2 \\
\hline 7 & -62 & -2.2 & 3 & -15 & -4.8 \\
\hline 8 & -66 & -5.9 & 4 & -62 & -7.1 \\
\hline 9 & +101 & -11.1 & 5 & -12 & -7.2 \\
\hline 11 & -5 & -18.9 & 6 & -26 & +11.2 \\
\hline 12 & -69 & -11.0 & 10 & +5 & -12.8 \\
\hline 13 & -51 & -10.4 & 14 & -17 & +0.1 \\
\hline 15 & +44 & -12.8 & 16 & -36 & +1.2 \\
\hline 17 & -69 & +3.4 & 18 & -9 & -6.2 \\
\hline 20 & -62 & -4.5 & 19 & -20 & -3.7 \\
\hline 23 & -80 & -8.4 & 21 & -37 & -0.7 \\
\hline 24 & -84 & -1.3 & 25 & -1 & -1.7 \\
\hline 26 & -59 & +13.4 & 27 & -69 & -0.5 \\
\hline 29 & -23 & +4.8 & 28 & -5 & -8.6 \\
\hline 30 & +14 & -1.5 & & & \\
\hline
\end{tabular}

Patient no. 22 was excluded (see text, results)

five patients, four were randomized for captopril treatment and one for atenolol.

The effects of both therapeutic regimens on haemodynamic parameters and renal function are shown in Table 1.Baseline values were not significantly different. The daily dose of captopril was $91 \pm 2 \mathrm{mg}$ and of atenolol $94 \pm 2 \mathrm{mg}$. Blood pressure was lowered to the same level in both treatment groups. During the first 6 months MAP decreased with captopril from $110 \pm 3$ to $102 \pm$ and total protein excretion, which are given as geometric means (antilog $95 \%$ confidence intervals of the logarithms).

${ }^{\mathrm{a}} p<0.01,{ }^{\mathrm{b}} p<0.05$ vs baseline

$2 \mathrm{~mm} \mathrm{Hg}(p<0.01)$ and with atenolol from $105 \pm 2$ to $101 \pm 2 \mathrm{~mm} \mathrm{Hg}(p<0.05)$. Blood pressure remained at a stable level thereafter (Fig. 1). After 24 months the percentual change of MAP was $-8.8 \pm 1.9 \%$ with captopril and $-4.1 \pm 1.6 \%$ with atenolol. The effect of both drugs on standing blood pressure was similar: baseline and 2year values were $138 / 90$ and $128 / 83$ with captopril, and $135 / 90$ and $128 / 85 \mathrm{~mm} \mathrm{Hg}$ with atenolol. Chlortalidone had to be given to two patients in the atenolol group and to six in the captopril group.

Renal function, as measured by GFR, did not differ between the two groups before treatment. In both groups GFR decreased significantly and to the same extent (Fig. 1 and Table 1). The mean rates of decline of GFR were $-4.9 \pm 2.1 \mathrm{ml} \cdot \mathrm{min}^{-1} \cdot$ year $^{-1}$ and $-3.7 \pm$ $1.6 \mathrm{ml} \cdot \mathrm{min}^{-1} \cdot$ year $^{-1}$ in the captopril- and atenololtreated patients, respectively. The rates of change in GFR in the individual patients are shown in Table 2. The greatest decline in GFR occurred during the first 6 months. Calculated from 6 months onwards, the decline in GFR was $-3.8 \pm 2.3$ and $-1.8 \pm 2.2 \mathrm{ml} \cdot \mathrm{min}^{-1}$. year $^{-1}$ in the captopril- and atenolol-treated patients, respectively (NS).

Urinary total protein and albumin excretion in the two groups were not significantly different at baseline. A significant reduction of proteinuria and albuminuria with both drugs was seen (Table 1 and Fig. 1). The relative change in albuminuria for the individual patients is shown in Table 2. The changes in albuminuria paralleled the change in MAP in both treatment groups. The greatest reduction occurred during the first 6 months. After 24 months the median change in 

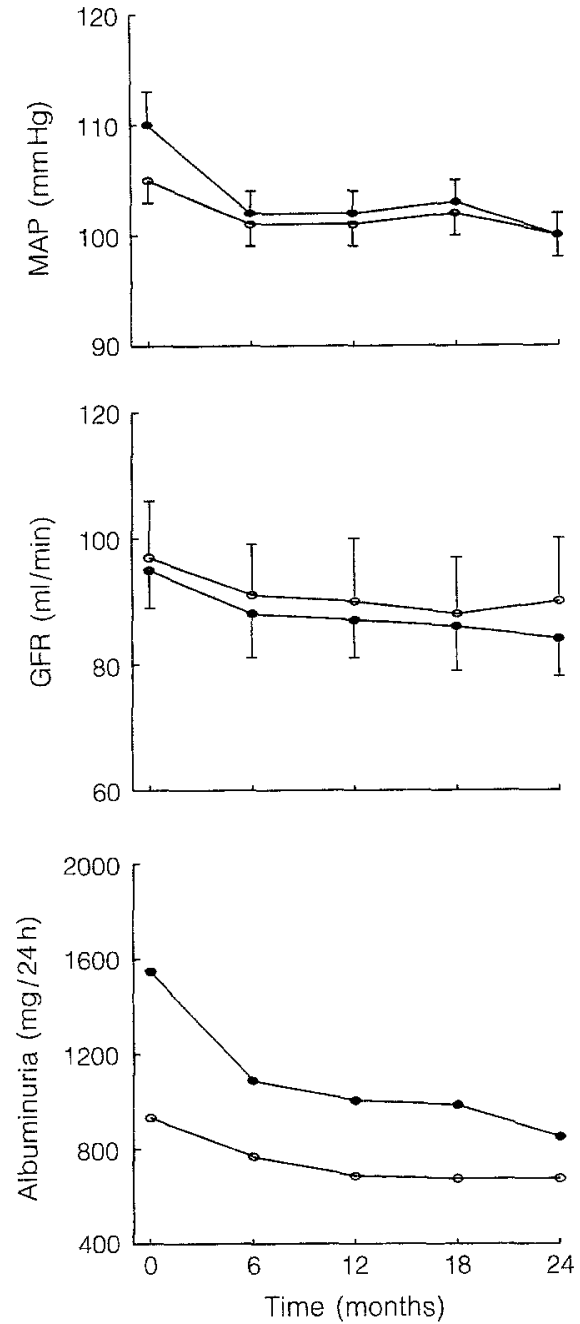

Fig.1. Effects of 2-year treatment with captopril ( $\bullet$ ) or atenolol ( $O$ ) on MAP, albuminuria and GFR in 29 patients with diabetic nephropathy. Blood pressure and albuminuria are the mean values of all measurements done during the preceding 6-month period. Results are given as mean $\pm \mathrm{SEM}$ (for MAP and GFR), or geometric mean (for albuminuria)

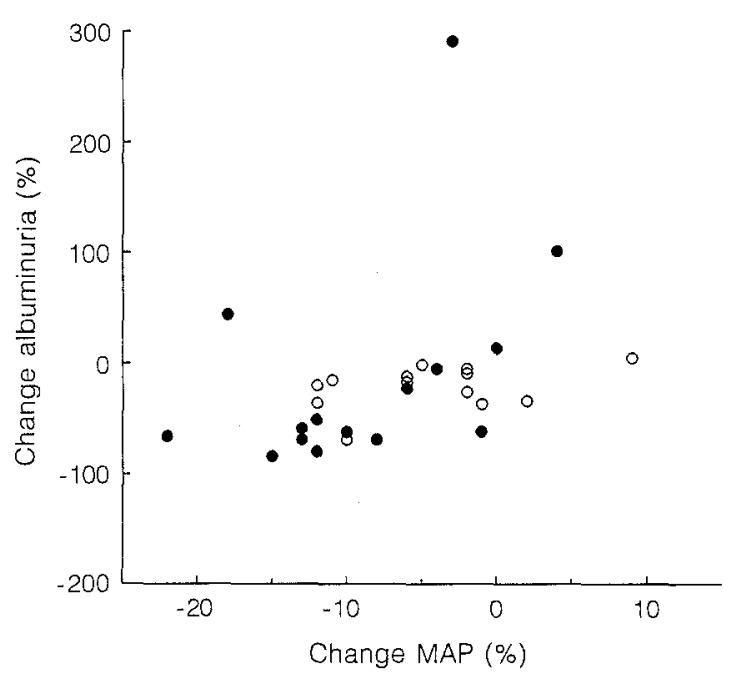

Fig.2. Correlation between relative change in albuminuria and the relative change in MAP after 2-years treatment with captopril $(\bullet)$ or atenolol $(O)$. Spearman correlation coefficient $\left(r_{\mathrm{s}}\right)=0.48(p<0.01)$ for all patients. For captopril $r_{\mathrm{s}}=0.53(p<0.05)$ and for atenolol $r_{\mathrm{s}}=0.15$ (NS) albuminuria was $-59 \%$ (range $-84 /+291$ ) and $18 \%(-69 /+5)$ with captopril and atenolol, respectively (NS). For all patients together the relative change in albuminuria after 2 years was significantly correlated with the relative change in MAP $\left(r_{\mathrm{s}}=0.48\right.$; $p<0.01$; Fig. 2). Analysis for each treatment group revealed a significant correlation in the captopril-treated patients $\left(r_{\mathrm{s}}=0.53 ; p<0.05\right)$ but not in the atenololtreated patients $\left(r_{\mathrm{s}}=0.15 ; \mathrm{NS}\right)$.

Curve analysis for MAP, albuminuria and GFR over the 2-year study period did not show significant differences between the two treatments.

Neither treatment regimen had a significant effect on glycaemic control. Mean $\mathrm{HbA}_{1 \mathrm{c}}$ during the entire period was $8.6 \pm 0.4 \%$ in the captopril-treated patients and $8.9 \pm 0.3 \%$ in the patients treated with atenolol. The effects of both treatments on other metabolic parameters are shown in Table 1. Notably, haemoglobin concentration was significantly lowered during the treatment with captopril.

In all the patients treated with captopril a rise in plasma renin activity was seen. In all the patients on atenolol heart rate was lowered. These observations suggest good compliance with drug treatment. No major side effects of either drug were seen during the study period. During the 24 months two patients, one on captopril (no.12) and one on atenolol (no.28), suffered from myocardial infarction, after 16 and 23 months treatment, respectively. Since the therapeutic regimen was not changed, except for the addition of acenocoumarol, with no change in blood pressure, these two patients completed the study.

Although overall albuminuria decreased, an increase was observed in five patients. On atenolol albuminuria increased $5 \%$ in one patient (no.10). In four patients (nos. 1, 9, 15 and 30) on captopril an increase in albuminuria was seen of 291, 101, 44 and $14 \%$, respectively. To determine whether these patients influenced the outcome of the study the data of these five patients were excluded. Re-analysis indicated that captopril decreased blood pressure and albuminuria to a greater extent than atenolol ( $\triangle \mathrm{MAP}-10.6 \pm 1.7$ vs $5.2 \pm 1.3 \% \quad(p<0.05)$ and $\Delta$ albuminuria $-62 \%(-$ $84 /-5)$ and $-20 \%(-69 /-1)(p<0.01)$ for captopril and atenolol, respectively). However, the rate of decline of GFR was still the same in both groups ($\left.3.7 \pm 2.1 \mathrm{vs}-2.9 \pm 1.5 \mathrm{ml} \cdot \mathrm{min}^{-1} \cdot \mathrm{year}^{-1}(\mathrm{NS})\right)$.

\section{Discussion}

Our study demonstrates that $\mathrm{ACE}$ inhibition and $\beta$ blockade are equally effective in retarding progression of diabetic nephropathy. Both drugs were well-tolerated and no major changes in metabolic parameters were observed. During captopril treatment a decrease in the haemoglobin concentration was noted as has been observed previously [11]. 
Experimental studies in rats have demonstrated that progression of renal disease is correlated with increased intraglomerular pressure [3]. In humans, intraglomerular pressure cannot be assessed directly, but it may be reflected in proteinuria. Furthermore, proteinuria is correlated with the progression of renal failure $[12,13]$. In our patients captopril clearly decreased protein excretion, which is in agreement with previous studies [14-16], but atenolol also reduced proteinuria to the same extent. Our data thus suggest that ACE inhibitors and $\beta$-blockers have equal antiproteinuric effects. Results of other studies comparing the antiproteinuric effects of ACE inhibitors and $\beta$-blockers in patients with diabetic and non-diabetic renal disease are equivocal [17-21]. An explanation for the seemingly contradictory results of these studies might be provided by the recent study of Weidmann et al. [22]. From their meta-analysis on the anti-proteinuric effects of antihypertensive drugs it becomes clear that ACE inhibition is superior to $\beta$-blockade in studies in which minimal reduction of blood pressure is achieved, whereas the differences become less clear at higher degrees of blood pressure reduction.

Recently, the question has been raised, whether urinary protein excretion should be used as a solid end point for studies designed to evaluate the effects of dietary or drug intervention on progression of renal disease [23]. The decrease in GFR over time, and ultimate progression to end-stage renal disease are more valid end points. Our study demonstrates equal rates of decline of GFR in both treatment groups. This conclusion is still valid when the data are analysed after exclusion of the five patients with an increase in proteinuria. The decline in GFR in our study is clearly slower than $10 \mathrm{ml} \cdot \mathrm{min}^{-1} \cdot$ year $^{-1}$, the value generally observed in untreated patients with overt diabetic nephropathy [15, 24]. Furthermore, from our data it is evident that GFR decreased predominantly in the first 6 months, which is probably related to the fall in blood pressure. Therefore, it can be expected that the rates of decline will be even slower at longer follow-up. This became apparent from 6 months onwards. Although we did not find a significant difference between decline of GFR in either treatment group, we cannot exclude that such a difference might become apparent when patients are studied over a more prolonged period of time. From our data it can be calculated that the chance that captopril is $50 \%$ better than atenolol in retarding deterioration of renal function is $4.8 \%$.

Björck et al. [17] conducted a study very similar to ours. They concluded that enalapril was more effective than metoprolol in retarding progressive diabetic nephropathy. However, their results are open for discussion. First, blood pressure reduction was less in metoprolol-treated patients. Moreover, in their analysis of the decline of GFR over time, data were included from patients who were followed-up for less than 1 year. As noted before, in the early treatment period a relatively large decrease in GFR is observed. This decrease is probably related to the abrupt decrease in blood pressure, and is probably not a reflection of ongoing renal damage. If the patients with a follow-up of less than 1 year are excluded from their study, the differences in the rates of decline of GFR between enalapril and metoprolol treatment are no longer significant. This conclusion is substantiated by the observation by Björck et al. that the decline of GFR from 6 months onwards is similar in the two treatment groups. The results of our study are in line with those of uncontrolled studies $[1,2,15,25-27]$ on antihypertensive treatment in diabetic nephropathy, in which no differences in effects of the various treatment modalities on change in GFR were found. In conclusion, our study suggests that treatment with captopril or atenolol is equally effective in retarding deterioration of renal function in IDDM patients with an early stage of nephropathy. It remains to be determined whether treatment over a longer period of time will lead to a different result. At present the data indicate that it is not the type of treatment but the treatment itself which is most important in changing the natural history of diabetic nephropathy.

Acknowledgements. We thank Mr. W.van de Broek (Department of Nuclear Medicine, University Hospital Nijmegen) for assistance with the GFR measurements, Ms. M. van Bergen and Ms. I. Wijnen for their care of the patients during all the visits to the out-patient clinic and Ms. J. Benneker and her staff (of the Department of Clinical Pharmacology) for the distribution of the medication. We thank Bristol-Meyers Squibb and ICIFarma who supplied captopril and atenolol tablets, respectively. The study was supported by a grant from the Dutch Kidney Foundation (C87.688).

\section{References}

1. Mogensen CE (1982) Long-term antihypertensive treatment inhibiting progression of diabetic nephropathy. BMJ 285: 685-688

2. Parving H-H, Andersen AR, Smidt UM, Svendsen PA (1983) Early aggressive antihypertensive treatment reduces rate of decline in kidney function in diabetic nephropathy. Lancet 1: 1175-1179

3. Hostetter TH, Rennke HG, Brenner BM (1982) The case for intrarenal hypertension in the initiation and progression of diabetic and other glomerulopathies. Am J Med 72: 375-380

4. Taguma Y, Kitamoto Y, Futaki G et al. (1985) Effect of captopril on heavy proteinuria in azotemic diabetics. $\mathrm{N}$ Engl $\mathrm{J}$ Med 313: 1617-1620

5. Elving LD, Wetzels JFM, De Nobel E, Hoitsma AJ, Berden JHM (1992) Captopril acutely lowers albuminuria in normotensive patients with diabetic nephropathy. Am J Kidney Dis 20: $559-563$

6. Rijk MCM, Van Lier HJJ, Van Tongeren JHM (1992) Relapse-preventing effect and safety of sulfasalazine and olsalazine in patients with ulcerative colitis in remission: a prospective, double-blind, randomized multicenter study. Am J Gastroenterol 87:438-442

7. Elving LD, Bakkeren JAJM, Jansen MJH, De Kat Angelino CM, De Nobel E, Van Munster PJJ (1989) Screening for microalbuminuria in patients with diabetes mellitus: frozen 
storage of urine samples decreases their albumin content. Clin Chem 35: 308-310

8. Drayer JIM, Benraad ThJ (1975) The reliability of the measurement of plasma renin activity by radioimmunoassay. Clin Chim Acta 61:309-324

9. Bröchner-Mortensen J, Rödbro P (1976) Selection of a routine method for determination of glomerular filtration rate in adult patients. Scand J Clin Lab Invest 36:35-43

10. Koziol JA, Maxwell DA, Fukushima M, Colmerauer ME, Pilch YH (1981) A distribution-free test for tumor-growth curve analysis with application to an animal tumor immunotherapy experiment. Biometrics 37: 383-390

11. Kamper A-L, Nielsen OJ (1990) Effect of enalapril on haemoglobin and serum erythropoietin in patients with chronic nephropathy. Scand J Clin Lab Invest 50: 611-618

12. Williams PS, Fass G, Bone JM (1988) Renal pathology and proteinuria determine progression in untreated mild/moderate chronic renal failure. Q J Med 252: 343-354

13. Remuzzi G, Bertani T (1990) Is glomerulosclerosis a consequence of altered glomerular permeability to macromolecules? Kidney Int 38: 384-394

14. Heeg JE, de Jong PE, van der Hem GK, de Zeeuw D (1987) Reduction of proteinuria by angiotensin converting enzyme inhibition. Kidney Int 32: 78-83

15. Parving H-H, Hommel E, Smidt UM (1988) Protection of kidney function and decrease in albuminuria by captopril in insulin dependent diabetics with nephropathy. BMJ 297: 1086-1091

16. Kloke HJ, Wetzels JFM, van Hamersvelt HW, Koene RAP, Kleinbloesem CH, Huysmans FThM (1990) Effects of nitrendipine and cilazapril on renal hemodynamics and albuminuria in hypertensive patients with chronic renal failure. $\mathrm{J}$ Cardiovasc Pharmacol 16:924-930

17. Björck S, Mulec H, Johnsen SA, Nordén G, Aurell M (1992) Renal protective effects of enalapril in diabetic nephropathy. BMJ 304:339-343

18. Erley CM, Harre U, Krämer BK, Risler T (1992) Renal hemodynamics and reduction of proteinuria by a vasodilat- ing beta blocker versus an ACE inhibitor. Kidney Int 41: $1297-1303$

19. Stornello M, Valvo EV, Scapellato L (1992) Persistent albuminuria in normotensive non-insulin-dependent (type 2) diabetic patients: comparative effects of angiotensin-converting enzyme inhibitors and $\beta$-adrenoceptor blockers. Clin Sci 82: 19-23

20. Kloke HJ, Wetzels JFM, Huysmans FThM, van Hamersvelt HW, Koene RAP (1993) Angiotensin converting enzyme inhibition and the combination of a beta blocker and a diuretic are equally effective in reducing proteinuria in patients with glomerulonephritis. Nephrol Dial Transplant 8: 808-813

21. Apperloo AJ, de Zeeuw D, Sluiter HE, de Jong PE (1991) Differential effects of enalapril and atenolol on proteinuria and renal haemodynamics in non-diabetic renal disease. BMJ 303: 821-824

22. Weidmann P, Boehlen LM, de Courten M (1993) Effects of different antihypertensive drugs on human diabetic proteinuria. Nephrol Dial Transplant 8: 582-584

23. Mogensen CE, Hansen KW, Østerby R, Damsgaard EM (1992) Blood pressure elevation versus abnormal albuminuria in the genesis and prediction of renal disease in diabetes. Diabetes Care 15: 1192-1204

24. Mogensen CE (1976) Progression of nephropathy in longterm diabetics with proteinuria and effect of initial antihypertensive treatment. Scand J Clin Lab Invest 36: 383-388

25. Parving H-H, Rossing P, Hommel E, Smidt UM (1992) Renal protective effects of captopril and metoprolol in diabetic nephropathy. Diabetologia 35 [Suppl 1]: A148 (Abstract)

26. Björck S, Nyberg G, Mulec H, Granerus G, Herlitz H, Aurell M (1986) Beneficial effects of angiotensin converting enzyme inhibition on renal function in patients with diabetic nephropathy. BMJ 293: 471-474

27. Parving H-H, Hommel E, Nielsen MD, Giese J (1989) Effect of captopril on blood pressure and kidney function in normotensive insulin dependent diabetics with nephropathy. BMJ 299: $533-536$ 